\title{
IGF-1 Regulates the Extracellular Level of Active MMP-2 and Promotes Müller Glial Cell Motility
}

\author{
Valeria E. Lorenc, ${ }^{1}$ Javier R. Jaldín-Fincati, ${ }^{1}$ José D. Luna ${ }^{2}$ Gustavo A. Chiabrando, ${ }^{1}$ \\ and María C. Sánchez ${ }^{1}$ \\ ${ }^{1}$ Centro de Investigaciones en Bioquímica Clínica e Inmunología (CIBICI-CONICET), Departamento de Bioquímica Clínica, Facultad \\ de Ciencias Químicas, Universidad Nacional de Córdoba, Córdoba, Argentina \\ ${ }^{2}$ Departamento de Vítreo-Retina, Centro Privado de Ojos Romagosa-Fundación VER, Córdoba, Argentina
}

Correspondence: María C. Sánchez, Departamento de Bioquímica Clínica, Centro de Investigaciones en Bioquímica Clínica e Inmunología (CIBICI-CONICET), Facultad de Ciencias Químicas, Universidad Nacional de Córdoba, Córdoba, Argentina;

csanchez@fcq.unc.edu.ar.

Submitted: June 15, 2015

Accepted: August 31, 2015

Citation: Lorenc VE, Jaldín-Fincati JR, Luna JD, Chiabrando GA, Sánchez MC IGF-1 regulates the extracellular level of active MMP-2 and promotes Müller glial cell motility. Invest Ophthalmol Vis Sci. 2015;56:6948-6960.

DOI: $10.1167 /$ iovs. $15-17496$
Purpose. In ischemic proliferative retinopathies, Müller glial cells (MGCs) acquire migratory abilities. However, the mechanisms that regulate this migration remain poorly understood. In addition, proliferative disorders associated with enhanced activities of matrix metalloproteinases (MMPs) also involve insulin-like growth factor (IGF)-1 participation. Therefore, the main interest of this work was to investigate the IGF-1 effect on the extracellular proteolytic activity in MGCs.

Methods. Cell culture supernatants and cell lysates of the human MGC line MIO-M1 stimulated with IGF-1 were analyzed for MMP-2 by zymographic and Western blot analysis. The MGCs' motility was evaluated by scratch wound assay. The MMP-2, $\beta 1$-integrin, and focal adhesions were detected by confocal microscopy. The localization of active MMPs and actin cytoskeleton were evaluated by in situ zymography.

RESULTs. The IGF-1 induced the activation of canonical signaling pathways through the IGF-1R phosphorylation. Culture supernatants showed a relative decrease in the active form of MMP2 , correlating with an increased accumulation of MMP-2 protein in the MGCs' lysate. The IGF1 effect on MMP-2 was abolished by an IGF-1R blocking antibody, $\alpha$ IR3, as well as by the PI3kinase inhibitor, LY294002. The IGF-1 increased the migratory capacity of MGCs, which was blocked by the GM6001 MMP inhibitor, LY294002 and $\alpha$ IR3. Finally, IGF-1 induced the intracellular distribution of MMP-2 toward cellular protrusions and the partial colocalization with $\beta 1$-integrin and phospo-focal adhesion kinase signals. Gelatinase activity was concentrated along F-actin filaments.

Conclusions. Taken together, these data indicate that IGF-1, through its receptor activation, regulates MGCs' motility by a mechanism that involves the MMP-2 and PI3K signaling pathway.

Keywords: glial cell, metalloproteinases, cell migration
Tnsulin-like growth factor 1 (IGF-1) is a 70-amino acid peptide belonging to a family of polypeptide trophic factors with mitogenic, differentiating, antiapoptotic, and metabolic functions. ${ }^{1}$ These biological actions are mediated by the IGF-1 receptor (IGF-1R), a member of the tyrosine kinase gene family of growth factor receptors. ${ }^{2}$ Upon IGF-1 binding, the activated IGF-1R promotes phosphorylation of specific cytosolic substrates, then the IGF-1 signal is transmitted to two downstream pathways: extracellular signal-regulated kinases 1 and 2 (ERK 1/2) and phosphatidylinositol 3-kinase (PI3K/AKT). ${ }^{1}$ Circulating IGF-1 is mainly released from the liver in response to pituitary growth hormone; however, a number of other tissues can also produce IGF-1 locally, including the central nervous system (CNS). ${ }^{3-5}$ Despite its peripheral location, the retina is part of the CNS, and there is considerable evidence that IGF-1 is important for neural and vascular retinal development. ${ }^{6,7}$ In addition, the IGF-1/IGF-1R system has also been implicated in retinopathies, and an increasing of IGF-1 levels has been found in vitreous samples from patients with proliferative diabetic retinopathy (PDR), ${ }^{8-10}$ whereas its participation in retinopathy of prematurity (ROP) appears to be more complex. ${ }^{11}$
Müller glial cells (MGCs) are the main glial cell type in the retina. They constitute an anatomic and functional link between retinal neurons and compartments to exchange molecules and play a crucial role in supporting neuronal development, survival, and information processing. ${ }^{12-15}$ The MGCs are also involved in the production and secretion of growth factors, including IGF-1. ${ }^{16,17}$ In pathologic conditions, such as PDR and proliferative vitreoretinopathy (PVR), ${ }^{18}$ MGCs adopt a number of drastic changes at the level of gene and protein expression, which impact on their morphology, migration, and proliferation, followed by extracellular matrix (ECM) degradation. This results in the formation of retinal membranes and resembles physiological processes of wound healing and fibrosis. ${ }^{19-21}$ Both metalloproteinase (MMP)-2 and MMP-9 have been associated with these processes, and MGCs are one type of MMP-producing cells in the retina. ${ }^{22,23}$ During proliferative retinopathy, MGCs encounter different ECM proteins, cytokines, and growth factors because these are often present in the vitreous humor and retinal tissues of affected eyes. $^{24-27}$ Therefore, MGCs' functions, including the production or regulation of matrix-degrading enzymes, may be 
influenced by cytokines and growth factors present in the retinal microenvironment. Whereas the MMP-9 expression was increased in MGCs stimulated by TNF- $\alpha,{ }^{22}$ we previously demonstrated that $\alpha_{2}$-macroglobulin $\left(\alpha_{2} M\right)$, an acute-phase response protein involved in retinopathies, induces MMP-2 activation and regulates membrane type 1 MMP (MT1-MMP) activity. ${ }^{28}$

Studies in models of CNS injury have demonstrated that the IGF-1/IGF-1R system stimulates cell migration of oligodendrocytes, ${ }^{29}$ astrocytes, ${ }^{30}$ and neuronal cells. ${ }^{31}$ However, there is no information about the IGF-1 effect on MGCs' migration in retinopathies. The evidence accumulated over the past three decades has demonstrated that the IGF-1 system plays an important role as a regulator of tumor cell invasion by modulating the MMP-2 synthesis and activity. ${ }^{32,33}$ Like other members of the MMP family, MMP-2 synthesis and function are regulated at multiple levels, including transcriptional activation, posttranscriptional processing, regulation of proteolytic activity by MT1-MMP, and inhibition through the tissue inhibitors of MMP (TIMP)..$^{34}$

MMP-2 is constitutively expressed and secreted in a latent form or pro-MMP-2 (72 kDa). Its activation to MMP-2 takes place at the cell surface and requires the participation of the active form of MT1-MMP that binds pro-MMP-2 on the cell membrane in a multimeric complex with TIMP-2. ${ }^{35}$ Enhanced expression or activity of MMP-2 was previously reported within retinal neovascular tissue, as well as in vitreous or aqueous samples from patients with PDR, ${ }^{36}$ suggesting that MMP-2 is an important therapeutic target in retinopathies. On the other hand, serum MMP-2 levels in these same diabetic patients were almost identical to control patients, indicating that increased levels of MMP-2 in the eyes were an ocular and not systemic consequence. In addition, numerous studies have reported high levels of IGF-1 in vitreous fluid of diabetic patients. $8,9,37$ However, the precise role of IGF-1 in the pathogenesis of retinopathies remains unclear. Our hypothesis is that IGF-1 plays a major role on the extracellular MMP-2 activity and cellular motility of MGCs during retinal ischemic proliferative disease. Thus, in the present study we investigated the IGF-1 effect on MMP-2 activity and cell migration in a wellcharacterized MGC line, MIO-M1.

\section{Materials AND Methods}

A spontaneously immortalized human MGC line (MIO-M1), kindly provided by G. Astrid Limb (UCL Institute of Ophthalmology and Moorfields Eye Hospital, London, UK), was used. ${ }^{38}$ Cells were grown in Dulbecco's modified Eagle's medium (DMEM; Invitrogen, Buenos Aires, Argentina) containing 4500 $\mathrm{mg} / \mathrm{L}$ glucose, sodium pyruvate) with $2 \mathrm{mM}$ L-glutamine (GlutaMAX; Invitrogen), 10\% vol/vol fetal bovine serum, and $50 \mathrm{U} / \mathrm{mL}$ penicillin/streptomycin (Invitrogen) at $37^{\circ} \mathrm{C}$ with $5 \%$ $\mathrm{CO}_{2}$. Recombinant human IGF-1 was purchased from SigmaAldrich Corp. (St. Louis, MO, USA). Immunoblots were performed with the following primary monoclonal antibodies: anti-phosphorylated ERK 1/2 (anti-p-ERK 1/2), polyclonal rabbit anti-total ERK 1/2, anti-calreticulin, and anti-MMP-2 (specific for the active form), all from Santa Cruz Biotechnology, Inc. (Santa Cruz, CA, USA). Rabbit monoclonal antiphospho-IGF-1R antibody was obtained from Cell Signaling Technologies, Inc. (Danvers, MA, USA). Mouse monoclonal anti-IGF-1R and MT1-MMP antibodies were both from Abcam, Inc. (Cambridge, MA, USA). Secondary antibodies used for immunoblotting were horseradish peroxidase-conjugated streptavidin (Thermo Fisher Scientific, Rockford, IL, USA). Dilutions for primary antibodies were between $1 / 250$ and 1/ 1000 , whereas for secondary antibodies they were $1 / 5000$. To block IGF-1/IGF-1R binding, cells were pretreated with a mouse monoclonal antibody specific against the IGF-1 receptor, aIR3 (Calbiochem, San Diego, CA, USA), at a final concentration of $16 \mathrm{nM}$. The inhibitory studies of ligand signaling included ERK 1/2 inhibitor PD-98059 and PI3K inhibitor LY-294002, both from Sigma-Aldrich Corp. Collagen type I (Col-I) or laminin used in the wound healing assays were also from Sigma-Aldrich Corp. To inhibit cell proliferation, hydroxyurea was used (Sigma-Aldrich Corp.). To block MMPs, a hydroxamate-based inhibitor $N-[(2 R)$-2(hydroxamideocarbonylmethyl)-4-methylpantanoyl]-L-tryptophan methylamide] (GM6001) was obtained (Calbiochem). To visualize cellular localization of proteins, we used two different monoclonal antibodies against MMP-2 (mouse anti-MMP-2 or rabbit antiMMP-2): a rabbit anti- $\beta 1$-integrin antibody (Abcam, Inc., Cambridge, MA, USA) and a mouse anti-phospo-focal adhesion kinase (p-FAK) antibody (Santa Cruz Biotechnology, Inc.). Secondary antibodies were raised in goat against rabbit or mouse IgG conjugated with Alexa Fluor 488 and 594, respectively (Molecular Probes, Eugene, OR, USA). The FITClabeled DQ-collagen and Alexa Fluor 594 phalloidin, used in an in situ zymography assay and in actin cytoskeleton labeling, were also purchased from Molecular Probes.

\section{Western Blot Assay}

To evaluate the IGF-1 effect on IGF-1R autophosphorylation and to investigate the involvement of the classical signaling pathways, MIO-M1 cells were plated in the presence or absence of IGF-1 (10 nM) for different periods of times. To evaluate the MMP-2 and MT1-MMP expression, MIO-M1 cells were incubated with IGF-1 (10 nM) for up to 8 hours. At the end of each treatment, cells at $70 \%$ to $80 \%$ confluence were kept on ice, and the medium was aspirated and lysed using nondenaturalizing buffer $(20 \mathrm{mM}$ Tris- $\mathrm{HCl}, 1 \%$ Triton $\mathrm{X}-100$, 10\% glycerol, $137 \mathrm{mM} \mathrm{ClNa}, 0.01 \% \mathrm{wt} / \mathrm{vol}$ bromophenol blue) containing phenyl methyl sulfonyl fluoride $(1 \mathrm{mM})$, sodium orthovanadate $(10 \mathrm{mM})$, and a protease inhibitor cocktail (Sigma-Aldrich Corp.). Protein concentrations were determined with a BCA protein assay kit (Pierce, Buenos Aires, Argentina) using albumin as standard. Aliquots containing proteins $(50 \mu \mathrm{m})$ were resolved on $10 \%$ SDSPAGE and transferred onto nitrocellulose membranes (Amersham Hybond ECL; GE Healthcare Bio-Sciences AB, Uppsala, Sweden). Nonspecific binding was blocked with $5 \%$ bovine serum albumin (BSA) in Tris-buffered salt containing $0.01 \%$ Tween-20, and the same solution was used to prepare primary antibodies, which were incubated with the membranes overnight at $4^{\circ} \mathrm{C}$. Membranes were incubated with a peroxidase-conjugated secondary antibody for 1 hour at room temperature (RT). Finally, the specific bands were revealed using a chemiluminescence kit (Thermo Fisher Scientific) and quantified by densitometric analysis using analysis software (Gel Pro Analyzer; Media Cybernetics, Inc., Rockville, MD, USA).

\section{Gelatin Zymography Assays}

Standard methodology for gelatin zymography was used to detect MMPs gelatinolytic activity in MIO-M1 cell supernatants as described previously by Kleiner and colleague. ${ }^{39}$ For this purpose, MIO-M1 cells $(5 \times 105$ cells/well $)$ were cultured at $37^{\circ} \mathrm{C}$ for 24 hours. The cells were then rinsed twice with serum-free medium, and $1 \mathrm{~mL}$ of DMEM-high glucose was added. Cells were stimulated with $10 \mathrm{nM}$ IGF-1 at different times (4-8 hours), after which the cell culture supernatants were collected. To block IGF-1/IGF-1R binding, cells were previously pretreated with $\alpha$ IR 3 in serum-free medium for 30 
minutes before ligand addition. Capillary blood was used as a positive control of MMP gelatinolytic activity. Aliquots of $30 \mu \mathrm{L}$ cell supernatants were resolved on 10\% SDS-PAGE/1.5\% gelatin (Sigma-Aldrich Corp.) in denaturing and nonreducing conditions. Gels were soaked for 1 hour with $2.5 \%$ Triton X-100 to remove the SDS, and the MMP activity was developed at $37^{\circ} \mathrm{C}$ in the enzyme buffer $(50 \mathrm{mM}$ Tris- $\mathrm{HCl}, 0.2 \mathrm{M} \mathrm{NaCl}$, and $5 \mathrm{mM}$ $\mathrm{CaCl}_{2}, \mathrm{pH} 7.5$ ) for 24 hours. After incubation, gels were stained for 30 minutes in $0.125 \%$ Coomassie blue R-250, and the stain was removed with the same solution without the dye until clear bands of gelatinolysis appeared on a dark background. The MMP-2 and MMP-9 were identified by molecular size using high-molecular-mass (14.5-200 kDa) standards (Bio-Rad, Hercules, CA, USA). Images were processed, and the intensity of the bands was obtained using the imaging program Gel Pro Analyzer (Media Cybernetics, Inc.).

\section{Biotinylation Assay}

A biotin-labeling protein assay using sulfo-NHS-SS-biotin (NoWeigh EZ-Link; Thermo Fisher Scientific) was performed following the manufacturer's procedure. Briefly, to evaluate MT1-MMP membrane expression, MIO-M1 cells were stimulated with IGF-1 (8 hours), washed with PBS, and incubated with sulfo-NHS-SS-biotin for 1 hour at $4^{\circ} \mathrm{C}$. After biotin incubation, cells were again washed and lysed with PBS $0.2 \%$ Triton $\mathrm{X}-100$ containing a protease cocktail inhibitor. Then $5 \mu \mathrm{L}$ of $20 \%$ agarose-streptavidin beads were incubated with the lysates $(100 \mu \mathrm{g})$ for 2 hours at RT. When the incubation was finished, the lysates were removed, the beads washed with PBS, and the bound proteins eluted. Equal amounts of eluted proteins were resolved on SDS-PAGE and blotted with an anti-MT1-MMP antibody. Results were quantified by ImageJ software (http://imagej.nih.gov/ij/; provided in the public domain by the National Institutes of Health, Bethesda, MD, USA).

\section{Cell Migration Assays}

Cell migration activities were examined by a two-dimensional scratch wound assay in six-well plates coated with Col-I $\left(10 \mu \mathrm{g} / \mathrm{cm}^{2}\right)$ or laminin $\left(1 \mu \mathrm{g} / \mathrm{cm}^{2}\right.$; Sigma-Aldrich Corp.). The MIO-M1 cells $\left(5 \times 10^{5}\right.$ cells/well) were cultured for 24 hours. In each well, a straight lesion was created in the center of the MIO-M1 cell monolayer with a sterile $10-\mu \mathrm{L}$ pipette tip. This technique produced a consistent wound devoid of cells, $\sim 35 \mathrm{~mm}$ long $\times 400 \mu \mathrm{m}$ wide. Wells were then rinsed twice with serum-free medium to remove any cell debris, and $2 \mathrm{~mL}$ of DMEM-high glucose without red phenol was added. Cells were treated with 10 nM IGF-1 for 12 hours. To block IGF-1/ IGF-1R binding, cells were pretreated with aIR3 for 30 minutes. In another set of experiments, to inhibit MMPs activity, cells were preincubated with GM6001 MMP inhibitor $(20 \mathrm{nM})$ for 30 minutes. ${ }^{28}$ In addition, to inhibit the activity of PI3K, cells were also pretreated with LY294002. In all the migration experiments and to inhibit cell proliferation, cells were preincubated with $0.5 \mathrm{mM}$ hydroxyurea.

Cellular migration was measured following a procedure previously described. ${ }^{28}$ Briefly, at selected times (0 and 12 hours), three random images of the wound per condition were acquired using a charge-coupled device camera (Nikon; Nikon, Inc., Melville, NY, USA) using bright-field microscopy (inverted microscope Nikon TU-2000; Nikon, Inc.) with a 10× objective (0.3 numerical aperture). Each image defined an average area of the wound equivalent to $5 \times 10^{5} \pm 1 \times 10^{4} \mu \mathrm{m}^{2}$ recorded to $t=0$ hours. Cells invading this area were counted to $t=12$ hours and results expressed as cells per area.

\section{Immunofluorescence Labeling and Confocal Microscopy}

To evaluate the cell distribution of MMP-2, $\beta 1$-integrin, and pFAK, MIO-M1 cells were grown to $30 \%$ to $70 \%$ confluence on glass coverslips coated with Col-I $\left(10 \mu \mathrm{g} / \mathrm{cm}^{2}\right)$ in 24 -well plates before being stimulated, or not, with IGF-1 (10 nM) for 8 hours. Coverslips containing the cells were washed twice with PBS, fixed in $4 \%$ paraformaldehyde (PFA) for 15 minutes at RT, permeabilized with $0.1 \%$ ( $\mathrm{vol} / \mathrm{vol}$ ) Triton $\mathrm{X}-100$, and blocked with $2 \%$ BSA for 1 hour at $37^{\circ} \mathrm{C}$ to block nonspecific binding sites. The coverslips were then incubated overnight at $4^{\circ} \mathrm{C}$ with primary antibodies diluted 1:50, washed three times with PBS plus 1\% BSA, and exposed to secondary antibodies diluted 1:800 for 45 minutes at RT. After a thorough rinse with PBS plus 1\% BSA, cell nuclei were stained at 1:1000 dilution (Hoechst no. 33258; Molecular Probes). Cells were washed with PBS and mounted on glass slides with reagent (Mowiol 488, Calbiochem; Merck KGaA, Darmstadt, Germany). Fluorescent images were obtained with a confocal laser-scanning biological microscope (Olympus FluoView FV1000; Olympus Corp., New York, NY, USA). Finally, images were processed with microscope software (FV10-ASW Viewer 3.1; Olympus Corp.) and with ImageJ software.

\section{In Situ Zymography}

To localize net pericellular proteolysis in MGCs, we used an in situ zymography assay described by Rivera. ${ }^{40}$ Briefly, after 12 hours of IGF-1 stimulus, migrating MGCs were rinsed in PBS and media was replaced by fresh media containing serum-free DMEM supplemented with calcium $\left(5 \mathrm{mM} \mathrm{CaCl}^{2}\right.$ in $50 \mathrm{mM}$ Tris, $\mathrm{pH}$ 7.6) and $100 \mu \mathrm{g} / \mathrm{mL}$ of FITC-labeled DQ-collagen that is intramolecularly quenched. Cells were incubated for 6 hours in a dark, humid chamber at $37^{\circ} \mathrm{C}$, rinsed in PBS, fixed in $4 \% \mathrm{PFA} /$ sucrose, and permeabilized with $0.1 \%$ (vol/vol) Triton X-100. For actin cytoskeleton labeling, nonspecific binding was blocked with $2 \%$ BSA for 1 hour at $37^{\circ} \mathrm{C}$. Cells were then incubated with Alexa Fluor 594 phalloidin, rinsed in PBS plus 1\% BSA, and incubated with Hoechst no. 33258 (1:1000 dilution). Finally, cells were mounted on glass slides with Mowiol 4-88 reagent. Collagen-FITC cleavage by cellular proteinases releases quenched fluorescence representative of net proteolytic activity. Cells incubated without DQ-collagen were not fluorescent.

\section{Statistical Methods}

For the densitometric quantifications and cellular migration assays, results were expressed as the mean plus or minus standard deviation of independent experiments; one-way ANOVA and a Tukey comparison posttest were used. For microscope quantifications of the level of colocalization, a JACoP plugin from ImageJ software was used. ${ }^{41}$ At least 50 cells per condition were analyzed. Differences from the control were considered significant at $P<0.05$.

\section{Results}

\section{IGF-1 Induces IGF-1R Phosphorylation and Intracellular Signaling Activation in MIO-M1 Cells}

To investigate the effect of IGF-1 on the intracellular signaling pathways activation in MGCs, we used the MIO-M1 cell line, which constitutively expresses IGF-1R (Lorenc VE, et al. IOVS 
2010;51:ARVO E-Abstract 5760; this study). Upon stimulation with IGF-1 (10 nM) for different periods of time $(1,5,10$, and 20 minutes), we clearly demonstrated by Western blot assays a time-dependent increase at the tyrosine phosphorylation of the 98-kDa IGF-1R $\beta$-subunit without an evident modification of the IGF-1R protein expression (Fig. 1A). In this period, the AKT and ERK 1/2 phosphorylation were also observed (Figs. 1B, 1C). The quantitative analysis revealed a significant increase of AKT phosphorylation from 5 minutes of IGF-1 treatment, whereas p-ERK 1/2 level was significant from 10 minutes of IGF-1 stimulation. These results indicate that the binding of IGF-1 to IGF-1R on MIO-M1 cells induced activation of both signaling pathways.

To demonstrate whether the IGF-1R phosphorylation and subsequent activation of PI3K/AKT and MAPK/ERK 1/2 pathways in MIO-M1 cells were specific responses to the IGF-1 binding to its receptor, we used a blocking antibody, $\alpha$ IR3, which specifically binds to the extracellular subunits of the IGF-1R. ${ }^{42}$ The pretreatment of MIO-M1 cells with $\alpha$ IR 3 for 30 minutes completely inhibited both IGF-1R and AKT phosphorylation induced by IGF-1 stimulation, while the levels of p-ERK $1 / 2$ returned to control level (Fig. 1D). The preincubation of $\alpha \mathrm{IR} 3$ alone did not produce any change in the phosphorylation levels of all molecules examined (Fig. 1D). In addition, AKT and ERK 1/2 phosphorylation induced by IGF1 were fully inhibited in the presence of LY-294002, a specific PI3K inhibitor, and PD980059, a Mek 1/2 inhibitor (data not shown)

\section{IGF-1 Regulates the Extracellular Levels of MMP-2 in MIO-M1 Cells}

In order to analyze the effect of IGF-1 on the extracellular levels of MMP-2 and MMP-9 secreted by MGCs, MIO-M1 cells were stimulated with IGF-1 $(10 \mathrm{nM})$ for different periods of time ( 4,6 , and 8 hours), and cell culture supernatants were analyzed by gelatin zymography assays. IGF-1-untreated MIO-M1 cells showed a constitutive expression of the proform of MMP-2 $(72 \mathrm{kDa})$ together with a minor presence of the active form $(62 \mathrm{kDa})$, which was well evidenced at 6 and 8 hours of cell culture, compared with untreated cells (Fig. $2 \mathrm{~A})$. In these experimental conditions, pro- and active forms of MMP-9 were undetectable and unaffected by the presence of IGF-1 (Fig. 2A). Then, to examine whether the effect of IGF-1 on the extracellular levels of MMP-2 active form was mediated by IGF-1R, MIO-M1 cells were cultured in the presence of $\alpha$ IR3 antibody. The preincubation of MIOM1 cells with blocking antibody abolished the IGF-1 effect on active MMP-2 without affecting the extracellular levels of pro-MMP-2 (Fig. 2B). Finally, to investigate whether IGF-1induced signaling pathways play any role on the extracellular levels of the active form of MMP-2 in MIO-M1 cells, PD$98059(20 \mu \mathrm{M})$ and LY-294002 $(10 \mu \mathrm{M})$ were used. The zymographic results showed that the preincubation of MIOM1 cells with LY-294002 restored the presence of the active MMP-2 in cell supernatants of MIO-M1 cells treated with IGF-1 (Fig. 2C). On the other hand, the pretreatment of the MIO-M1 cells with PD-980059 (Fig. 2C) did not produce significant changes in the MMP-2 activity, indicating that the PI3K/AKT but not MAPK/ERK 1/2 pathway is involved in the IGF-1 effect on the extracellular levels of active MMP-2. Phospho-specific antibodies to ERK $1 / 2$ or AKT confirmed that, at the concentrations used, PD-98059 did not affect AKT phosphorylation and LY-294002 did not affect MAPKERK 1/2 signaling (data not shown).

\section{IGF-1 Produces Cell Lysate Accumulation of MMP-2 Without Modifying the Cell Surface Expression of MT1-MMP in MIO-M1 Cells}

Considering the zymographic results obtained above, we decided to analyze the presence of MMP-2 protein in cell lysates and culture supernatants by Western blot assays, using a monoclonal antibody that specifically recognizes the active form of this MMP, in MIO-M1 cells incubated with IGF-1. Figure 3 shows that the active MMP-2 $(62 \mathrm{kDa})$ was only detected in culture supernatants of nonstimulated MIO-M1 cells for 8 hours, whereas under IGF-1 treatment active MMP-2 was undetectable during this time. However, the nondetection of active MMP- 2 in supernatants of nonstimulated MIO-M1 cells for 4 and 6 hours may be due to the low concentration of this isoform, which was undetectable by the Western blot assay. By contrast, the analysis of cell lysates showed that active MMP-2 was detected in MIO-M1 cells treated with IGF-1 for 6 and 8 hours but not in nonstimulated cells. These results suggest that IGF-1 induces the cell surface anchoring of active MMP-2 together with a significant decrease at the extracellular level.

Since the pro-form of MMP-2 is converted to the active form on the cell surface by MT1-MMP, ${ }^{43,44}$ we also analyzed the MT1MMP protein expression in MIO-M1 cells treated with IGF-1. Western blot analysis revealed that at 8 hours of IGF-1 treatment the MT1-MMP expression increased in MIO-M1 cells (Fig. 4A). Then, to determine whether the IGF-1 treatment produced MT1-MMP accumulation on the cell plasma membrane, a sulfo-NHS-SS-biotin-labeling cell surface protein assay was used. To carry out the assay, MIO-M1 cells were treated with IGF-1 for 8 hours, followed by biotin labeling, as detailed in the Materials and Methods section. Results showed that the amount of biotinylated MT1-MMP at cell surface level was not modified after stimulation with IGF-1 (Fig. 4B). These results indicate that the increase in MT1-MMP under IGF-1 stimulation was not correlated with an enhanced presence of this membrane protein at cell surface level, suggesting that MT1MMP is not involved in the decrease of the active form of MMP2 at the extracellular level.

\section{IGF-1 Induces MIO-M1 Cell Migration Mediated by Its Cognate Receptor}

To determine whether IGF-1/IGF-1R system is functionally involved in MGC migration, we used a two-dimensional scratch wound assay where MIO-M1 cells were cultured in laminin and Col-I-coated plates. Since we have already demonstrated by bromodeoxyuridine assay that IGF-1 (12 hours) was able to induce MIO-M1 cell proliferation (data not shown), these migration assays were carried out in the presence of hydroxyurea, a known pharmacologic inhibitor of cell proliferation. Figure $5 \mathrm{~A}$ shows representative scratch wound assays of MIO-M1 cells cultured in Col-I-coated plates stimulated or not with IGF-1 $(10 \mathrm{nM})$ at the beginning (0 hours) and at the end (12 hours) of each experiment. In this experiment it is observed that an enhanced number of cells are invading the wound area in the presence of IGF-1 with respect to nonstimulated cells. Bar graphs represent the quantitative analysis of migration assays performed in laminin- and Col-Icoated plates. In this way, results revealed that in the absence of IGF-1 MIO-M1 cells cultured in Col-I-coated plates enhanced the cell number invading the wound area, compared with laminin-coated plates. However, IGF-1 significantly increased the number of cells migrating to the wound area after 12 hours of stimulus in both ECM proteins when compared to untreated cells.

To examine whether the IGF-1-induced cell migration is mediated by IGF-1R, MIO-M1 cells were previously treated with 
A

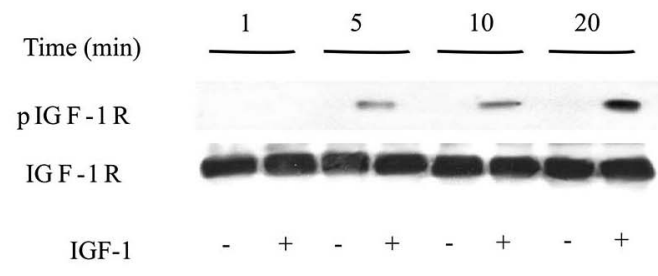

$\mathrm{B}$

$\mathrm{C}$
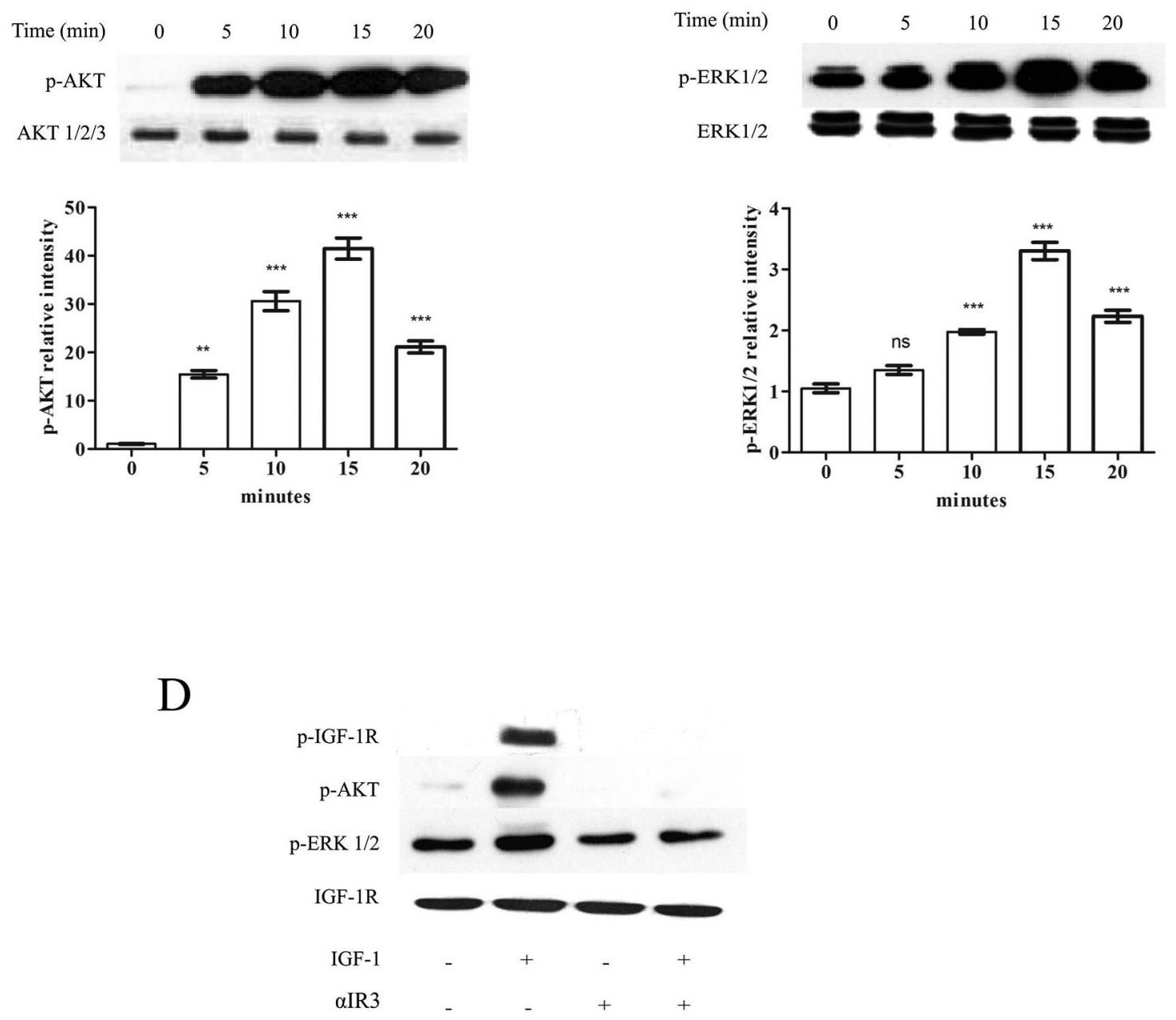

FigURE 1. IGF-1 induces IGF-1R autophosphorylation and downstream activation of intracellular signaling pathways in MIO-M1 cells. (A) Western blot analysis of phosphorylated IGF-1R (p-IGF-1R) in MIO-M1 cells cultured in the presence of $10 \mathrm{nM}$ IGF-1 at indicated times. IGF-1R is shown as a loading control. (B) Representative Western blot assay of phosphorylated AKT (p-AKT) in MIO-M1 cells cultured in the presence of 10 nM IGF-1 at indicated times. AKT $1 / 2 / 3$ is shown as a loading control. The bars represent the densitometric analysis of the immunoreactive protein expressed as relative intensity calculated from the densitometric intensity of p-AKT signal normalized to AKT 1/2/3. Bars represent the mean \pm SD of three independent experiments. The asterisks show statistical differences with respect to control ( 0 minutes) for $P<0.01(* *)$ and $P<0.001(* * *)$, respectively. (C) Representative Western blot assay of phosphorylated ERK 1/2 (p-ERK 1/2) in MIO-M1 cells cultured in the presence of 10 nM IGF-1 at indicated times. ERK $1 / 2$ is shown as a loading control. The bars represent the densitometric analysis of the immunoreactive protein expressed as relative intensity calculated from the densitometric intensity of p-ERK $1 / 2$ signal normalized to ERK $1 / 2$. Bars represent the mean \pm SD of three independent experiments. ns, nonsignificant. The asterisks show statistical differences with respect to control $(0$ minutes) for $P<0.001(* * *)$. (D) Western blot assay of lysates from cells preincubated (or not) with the $\alpha$ IR3 antibody in the presence or absence of 10 nM IGF-1, showing p-IGF-1R, p-AKT, and p-ERK 1/2 levels. IGF-1R is shown as a loading control. 
A

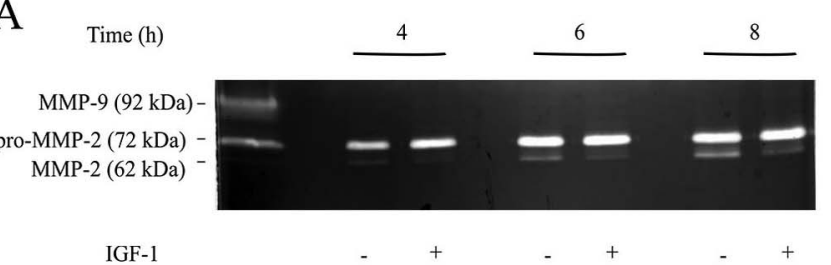

B
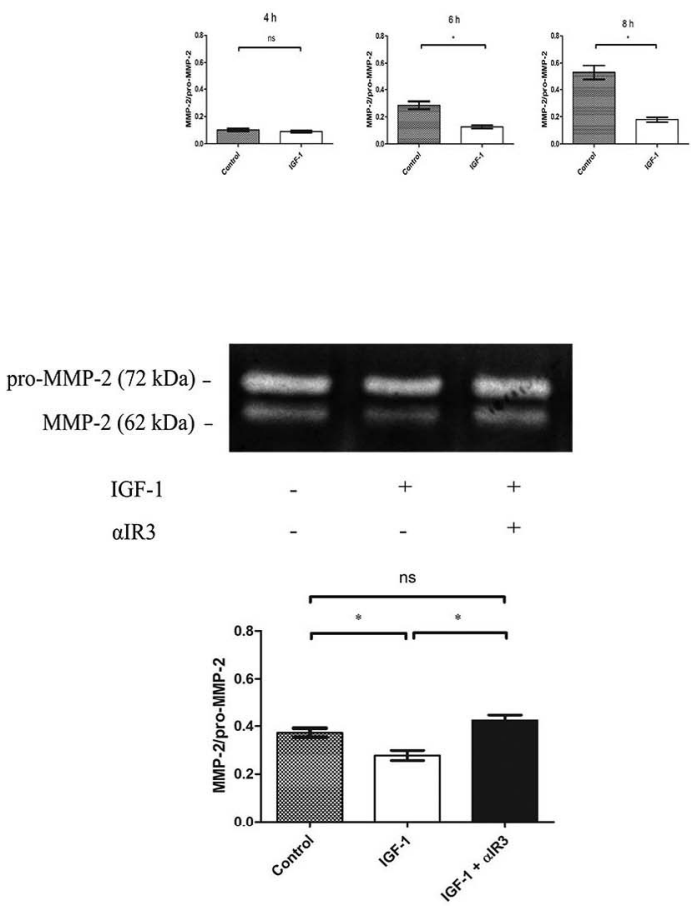

$\mathrm{C}$

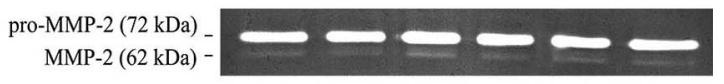

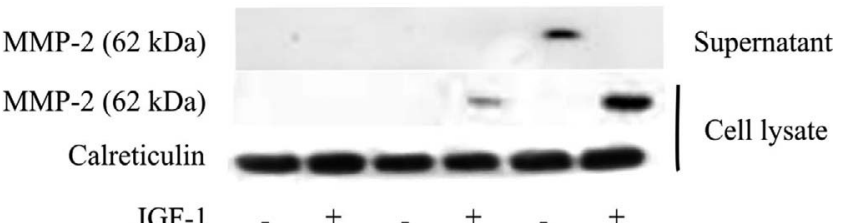

Figure 3. IGF-1 produces an accumulation of active MMP-2 in cell lysates. Western blot assay for the determination of active MMP-2 from lyophilized culture supernatants and cell lysates of MIO-M1 cells cultured in the presence of $10 \mathrm{nM}$ IGF-1 using an antibody that specifically recognizes the active MMP-2. Calreticulin is shown as a loading control.

aIR3 antibody. Figure 5B shows that the pretreatment of MIOM1 cells with $\alpha$ IR3 antibody significantly blocked the effect of IGF-1 on the cell migration, indicating that this process was mediated by IGF-1R. Next, to evaluate the specific role of MMP2 in the cellular migration induced by IGF-1, MIO-M1 cells were pretreated with GM6001, a well-established MMP inhibitor. Interestingly, IGF-1-induced cellular migration was also significantly reduced by this inhibitor (Fig. 5B), indicating that MMP2 activity played a critical role in the migratory process mediated by IGF-1. Finally, and considering that the PI3K/AKT signaling pathway participates in the regulation of the extracellular MMP-2 levels, we examined the IGF-1-induced MIO-M1 migration in cells pretreated with LY294002. In this way, a significant reduction in the cell motility to wound area was also observed (Fig. 5B).

\section{IGF-1 Induces the Partial Colocalization of MMP-2 With $\beta 1$-integrin and p-FAK at the Cell Protrusions}

Functional interactions exist between integrins and MMP-2 in cell types with migratory phenotypes, ${ }^{45-47}$ including astrocytes $^{40,48}$ and probably MGCs. With this in mind, by confocal microscopy, we examined the cellular distribution of $\beta 1$ integrin and MMP-2 in nontreated and IGF-1-treated MGCs. Figure 6A shows that in the absence of IGF-1, both $\beta 1$-integrin and MMP-2 showed a punctate perinuclear distribution with certain fluorescence spread over the cell periphery. Under this experimental condition, both proteins showed a low degree of colocalization. However, under IGF-1 stimulus (8 hours), an increased proportion of $\beta 1$-integrin and MMP- 2 colocalized in the cell periphery, preferentially at the leading edge associated with lamellipodia or cellular protrusions, without changes in perinuclear regions with respect to nonstimulated cells. The quantitative analysis showed that in cellular protrusions, $\beta 1$ integrin and MMP-2 signals partially colocalized $(\sim 18 \%)$ in MIO-M1 cells cultured in the presence of IGF-1, with respect to nonstimulated cells $(\sim 3 \%)$. By contrast, in perinuclear regions, although $\beta 1$-integrin also showed a certain level of colocalization with MMP-2 ( 18\%), this proportion was not significantly modified by IGF-1 (Fig. 6B).

stimulated with IGF-1 for 8 hours. In each case, bands corresponding to pro-MMP-2 and MMP-2 were quantified by densitometric analysis, and their relations are represented in the bar graphs expressed in arbitrary units. Bars denote the mean \pm SD from triplicate experiments. ns, non significant. The asterisks show statistical differences with respect to control for $P<0.05\left(^{*}\right)$. 
A
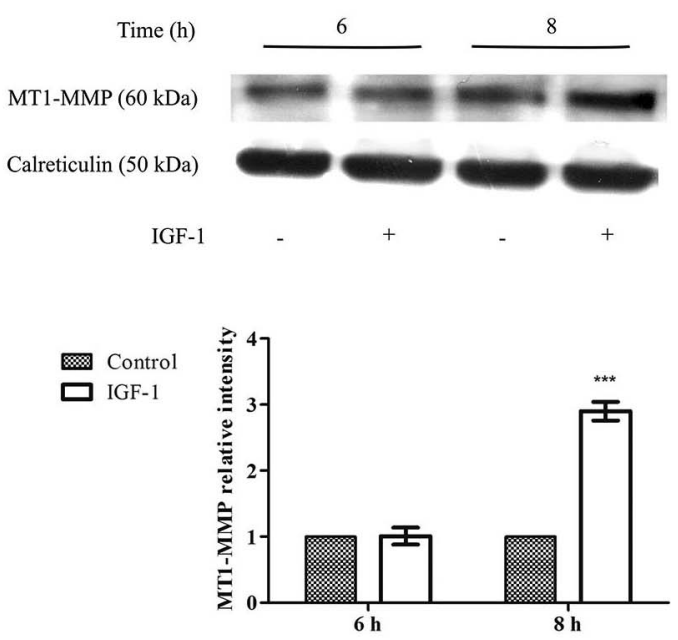

B

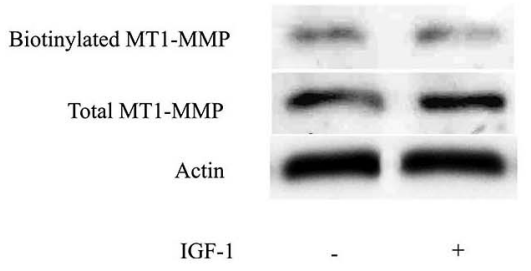

Figure 4. IGF-1 does not modify the MT1-MMP expression at cell surface level. (A) Representative Western blot assay for the determination of MT1-MMP in MIO-M1 cells cultured in the presence of $10 \mathrm{nM}$ IGF-1 at indicated times. Calreticulin is shown as a loading control. The bars represent the densitometric analysis of the immunoreactive protein expressed as relative intensity calculated from the densitometric intensity of the MT1-MMP signal normalized to calreticulin. Bars represent the mean \pm SD of three independent experiments. The asterisks show statistical differences with respect to control for $P<$ $0.001^{(* * *)}$. (B) Cells were treated (or not) with IGF-1 $(10 \mathrm{nM})$ for 8 hours, and the cell surface level of MT1-MMP was evaluated by a biotinlabeling protein assay and immunoblotted for MT1-MMP. Biotinylated MT1-MMP: Represents the biotinylated-bound and eluted fraction of the streptavidin-agarose beads. Total MT1-MMP: The input (10\%) of biotinylated proteins is shown. Actin was used as protein-loading control.

Having established a partial colocalization of MMP-2 and $\beta 1$ integrin in the periphery of the cell, and considering that FAK is an important nonreceptor protein tyrosine kinase involved in the cell-ECM adhesion, ${ }^{49}$ we next assessed the cellular distribution of p-FAK (active form) and MMP-2 in human MGCs. In the absence of IGF-1, p-FAK was concentrated at the edges of the membrane ruffles (Fig. 7A, top), whereas under IGF-1 stimulus (8 hours) an intense staining was observed in small foci within lamellipodia and filopodia (Fig. 7A, bottom). The merged image for p-FAK/MMP-2 indicated that both proteins partially colocalized in cellular protrusions (Fig. 7A, bottom). The quantitative analysis showed that in perinuclear regions the fluorescence of p-FAK and MMP-2 colocalization was similar in control and IGF-1 stimulus ( 4\%) (Fig. 7B). By contrast, in cellular protrusions the percentage of p-FAK/MMP2 colocalization was significantly increased $(\sim 12 \%)$ after IGF-1 treatment (Fig. 7B).

\section{IGF-1 Induces the In Situ Proteolytic Activity Concentrated Along F-Actin Filaments}

Considering that IGF-1 induced a marked MMP-2 localization in the cellular protrusions of MGCs, we next assessed whether this MMP distribution correlated with an increased pericellular proteolysis. To do this, in situ zymography assays containing DQ-collagen as substrate were carried out as detailed in the Materials and Methods section. With this substrate, both gelatinase and collagenase activity of MMPs may be analyzed, although other proteinases can also produce the proteolysis of DQ-collagen substrate. Confocal microscopy analysis showed that in the absence of IGF-1, the proteolytic activity was mainly concentrated in perinuclear regions, and in some cells this activity was weakly associated with cortical actin (Fig. 8A). By contrast, MGCs stimulated with IGF-1 exhibited proteolytic activity mainly distributed along the migration front in areas of actin-rich filopodia and associated with cortical actin (Fig. 8B, 8C). Analysis at high-power magnification revealed that the DQ-collagen proteolytic activity was oriented along actin filaments in most cell filopodia of migrating MGCs. Our results demonstrate that the accumulation of MMP-2 in cellular protrusions was associated with an increased pericellular proteolysis in MGCs stimulated with IGF-1.

\section{Discussion}

IGF-1 is a polypeptide hormone that binds to its specific receptor, IGF-1R, and exerts biological actions by activating several intracellular signaling cascades, such as MAPK/ERK 1/2 and PI3K/AKT pathways. ${ }^{1,50}$ Several studies have shown that these pathways may in fact be interdependent, as they exert regulatory control on each other. ${ }^{33,51-53}$ Depending on the cell type studied, the concentration, and the time course of the IGF-1 stimulus, different effects in pericellular proteolytic activity under physiological and pathologic processes have been reported. ${ }^{54}$ To our knowledge, this is the first demonstration that IGF-1 in retina, through IGF-1R, decreases the extracellular level of MMP-2 active form and induces MGC migration. Considering that both IGF-1 effects were inhibited by the pharmacologic inhibitor, LY294002, we conclude that the PI3K/AKT pathway is involved in these extracellular and migratory events of MGCs.

As previously described for other cell types, Western blot analysis showed that after IGF-1R autophosphorylation, IGF-1 also induced the phosphorylation of AKT and ERK 1/2 in MGCs. However, the PI3K/AKT pathway was differentially activated because significant phosphorylated AKT levels were observed at shorter times of IGF-1 stimulation compared with the IGF-1 effect on phosphorylated ERK 1/2. In addition, the pretreatment of MIO-M1 cells with the $\alpha$ I3R antibody inhibited IGF-1R autophosphorylation as well as subsequent signaling events, indicating that both signaling pathways were activated by IGF-1 in retinal MGCs. In agreement with our observations, various authors have previously identified IGF-1R as a regulator of MMP-2 synthesis or activity via PI3K/AKT signaling pathway in cancer cells. ${ }^{54,55}$ At the same time, Zhang and colleagues ${ }^{33}$ have demonstrated in a tumor cell model that low to moderate levels of IGF-1 caused the activation of PI3K/AKT pathways, which in turn inhibited the ERK pathway through AKTmediated Raf phosphorylation. High levels of stimulating IGF1 overcame this inhibition and led to ERK induction. The PI3K/ AKT pathway stimulated the MMP-2 expression, whereas the Raf/MEK/ERK pathway was inhibitory. In our MGC model, PI3K/AKT pathway activated by IGF-1 was also involved in MMP-2 regulation evidenced by a reduction of the active form at the extracellular level. 
A

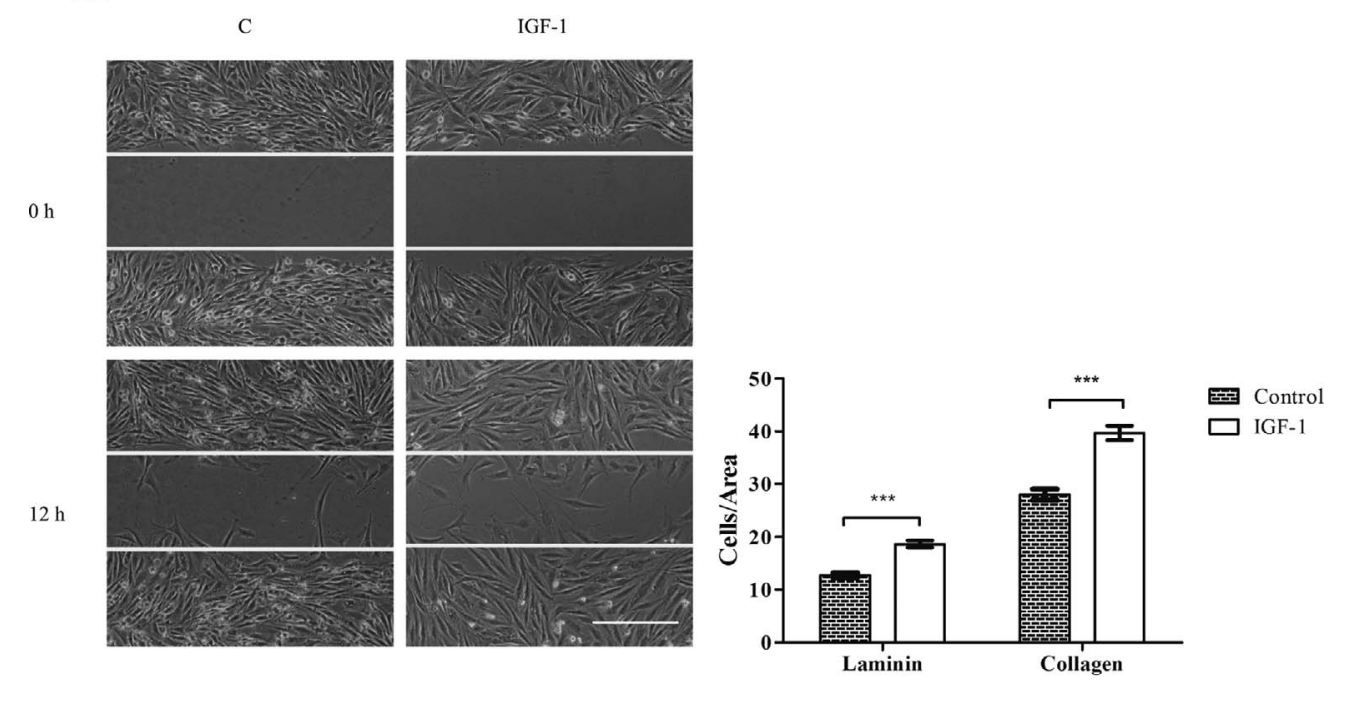

B

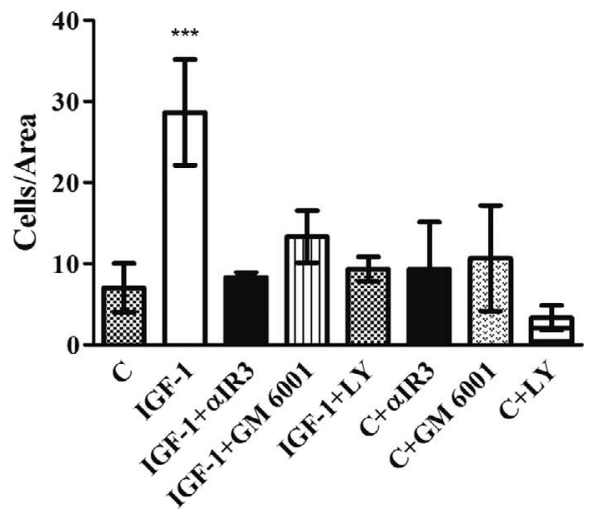

FiguRE 5. IGF-1 induces MIO-M1 cell migration through its cognate receptor. (A) Representative two-dimensional scratch wound assay of MIO-M1 cells cultured in plates coated with collagen type I (collagen) in the presence or absence of IGF-1 (10 nM) during 12 hours. Scale bar: $100 \mu \mathrm{m}$. Bar graph represents mean values \pm SD of the cell number invading the area of the wound (cells/area) in the absence (control) or presence of IGF-1 (10 $\mathrm{nM}$ ) in plates coated with laminin or collagen. (B) Quantitative analysis of MIO-M1 cell migration by scratch wound assay of cells cultured in

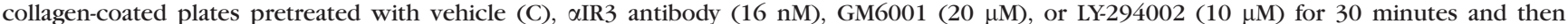
stimulated with IGF-1 (10 nM) for 12 hours. Bar graph represents mean values \pm SD of the cell number invading the area of the wound (cells/area). Three independent experiments were performed in triplicate. The asterisks show statistical differences with respect to control for $P<0.001$ (***).

In normal cells, previous studies have also demonstrated that PI3K activation causes the dedifferentiation of vascular smooth muscle cells (VSMCs) and stimulates VSMC migration by IGF-1-mediated MMP-2 upregulation. ${ }^{54}$ In the current study, we showed by zymography that supernatants of MIO-M1 cells treated with IGF-1 presented a significant reduction in the active form of MMP-2 compared with untreated cells. In this way, it was established that the migration of both normal and cancer cells depended on MMP accumulation at membrane protrusions, which is required for the focal pericellular degradation of ECM. ${ }^{56}$ In line with this, we decided to evaluate MMP-2 active expression by Western blot assays, using a specific antibody that recognizes only the active form of this MMP. Results revealed that IGF-1 produced an increased accumulation of the active form of MMP-2 in MIO-M1 cells. By a biotin-labeling cell surface protein assay, we can also confirm that the amount of MT1-MMP at the cell surface was not modified after IGF-1 stimulus. Hence, this particular increase of MMP-2 in MIO-M1 would confer the focal gelatinolytic activity necessary for supporting a migratory phenotype.

It is known that in Col-I matrix, MT1-MMP initiates denaturation of collagen into gelatin, which is subsequently digested by MMP-2, facilitating pericellular proteolysis and enhancing cell invasion and migration. Furthermore, it has been suggested that the intracellular traffic of MT1-MMP toward the cell surface and its participation in cellular migration may be dependent on the tumoral or nontumoral characteristics of cells, as well as on the presence of extracellular factors that induce cellular migration, such as Col- $\mathrm{I}^{57}$ and $\alpha_{2} \mathrm{M}^{28}$ among others. ${ }^{44}$ Using two-dimensional scratch wound assays, we demonstrated that, in fact, in the 

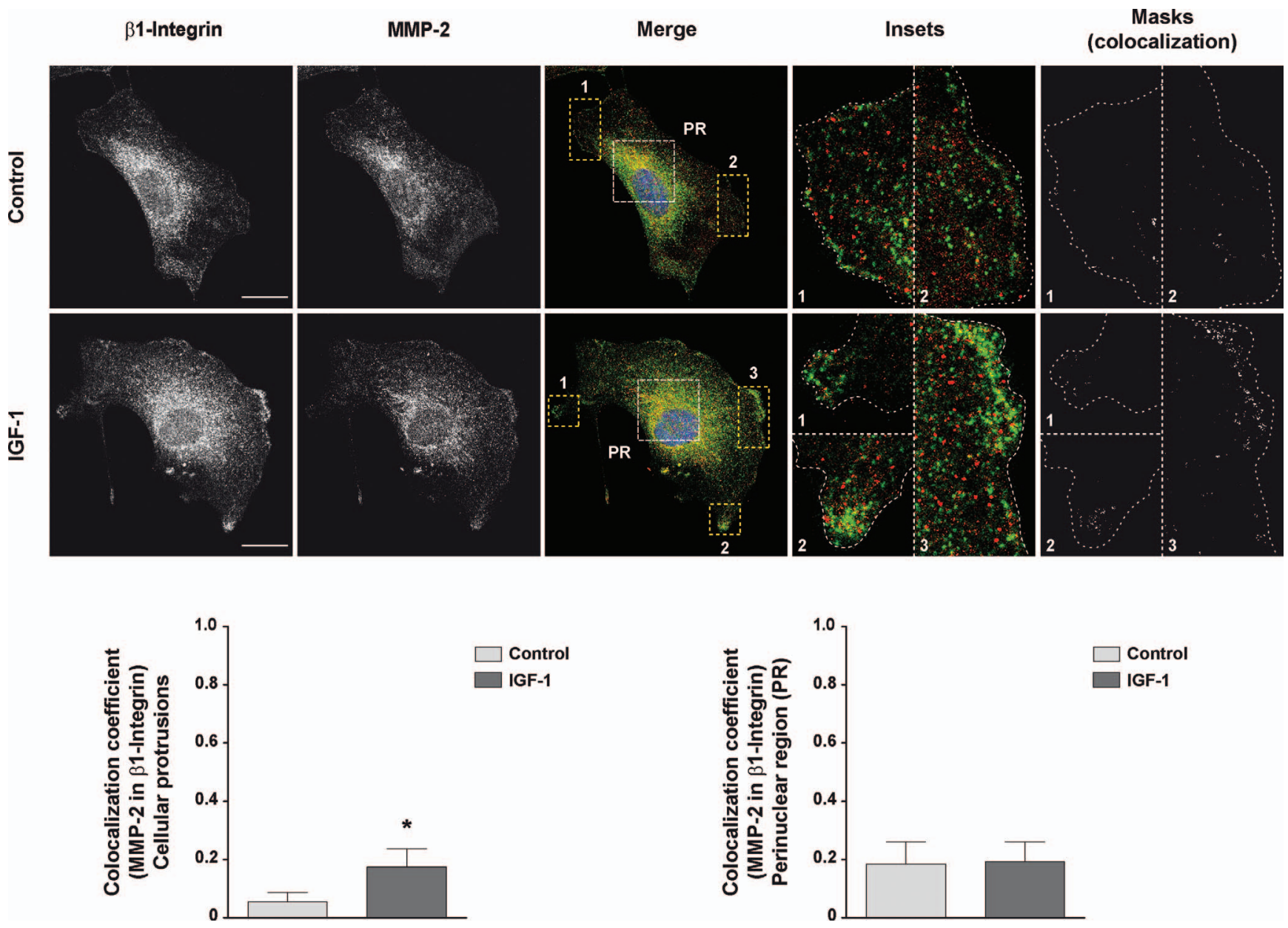

FIGURE 6. $\quad \beta 1$-integrin and MMP-2 colocalization is increased in MIO-M1 cells stimulated with IGF-1. The top two rows show representative images obtained by confocal microscopy. The MIO-M1 cells were cultured in glass coverslips coated with Col-I in the absence (control) or presence of IGF-1 $(10 \mathrm{nM})$ for 8 hours. Then, $\beta 1$-integrin was immunodetected using a polyclonal rabbit antibody, whereas for MMP-2 a mouse monoclonal antibody was used. The overlaid images are magnifications of the protrusions (insets 1 and 2 or $1-3$ ) of the cells (boxes) for $\beta 1$-integrin and MMP-2 detection. In masks 1 and 2 or 1, 2, and 3, $\beta 1$-integrin and MMP-2 colocalizations are observed. Quantification of colocalization levels between $\beta 1$-integrin and MMP-2 was performed in cellular protrusions and perinuclear regions (PR) and is represented in the bar graph. Three independent experiments were performed in triplicate. ${ }^{*} P<0.05$ indicates statistical significance with respect to control. Scale bar: $20 \mu \mathrm{m}$.

absence of IGF-1 the cellular migration of MIO-M1 cells was increased in the presence of Col-I with respect to laminin. However, IGF-1 increased the migratory ability of MGC independently from the ECM proteins used as cell support. The blockade of IGF-1R autophosphorylation with $\alpha$ IR3 antibody inhibited the migratory process, which indicates that IGF-1 is an extracellular factor inducing cell motility of MIO-M1 cells independently from the presence of Col-I per se. Experiments performed with the synthetic MMP inhibitor GM $6001^{58}$ revealed that this agent efficiently inhibits the migration of MIO-M1 cells through inactivation of MMPs. In addition, LY 294002 also decreased the MIO-M1 cell migration in another set of scratch wound experiments. These results clearly indicate that MIO-M1 cell migration requires the activity of MMP-2 and PI3K/AKT signaling pathways.

In the present work, we observed that, under IGF-1 stimulus, MIO-M1 cells acquired migratory properties characterized by the MMP-2 redistribution to cellular protrusions. In this way, it was established that pericellular focalization of proteolytic activity is required for adhesion and de-adhesion processes that underlie cell motility. ${ }^{59}$ Previous work in cancer cells have shown that membrane-linked MMP-2 is an important element for tumor cell invasion through its link with integrins. ${ }^{45,47}$ Herein, we showed that IGF-1 induced the redistribution of MMP-2 in migrating cells. In these conditions, a focalized peripheral distribution of MMP-2 across the cellular protrusions replaced the pattern of distribution observed in control cells, supporting the idea that MMP-2 is recruited to specific areas at the leading edge of migrating MGCs. A similar peripheral pattern was also observed for $\beta-1$ integrin and p-FAK proteins under IGF-1 stimulus. It is known that the ligand occupancy of different integrins regulates cell adhesion and migration processes, which often involve formation of focal adhesions. ${ }^{60-62}$ Here, the interactions of integrins with actincontaining complexes led to activation of signaling events, including phosphorylation of FAK. Integrins have been implicated in cellular migrations in many contexts. These include leukocyte trafficking in immune surveillance, movements that mediate tissue regeneration and repair, and migration during embryonic morphogenesis, among others. ${ }^{63-65}$ Many human diseases, including retinopathies, have been associated with altered integrin-mediated adhesion and migration. ${ }^{66-68}$ Therefore, there has been strong interest in understanding and potentially targeting integrin-mediated 

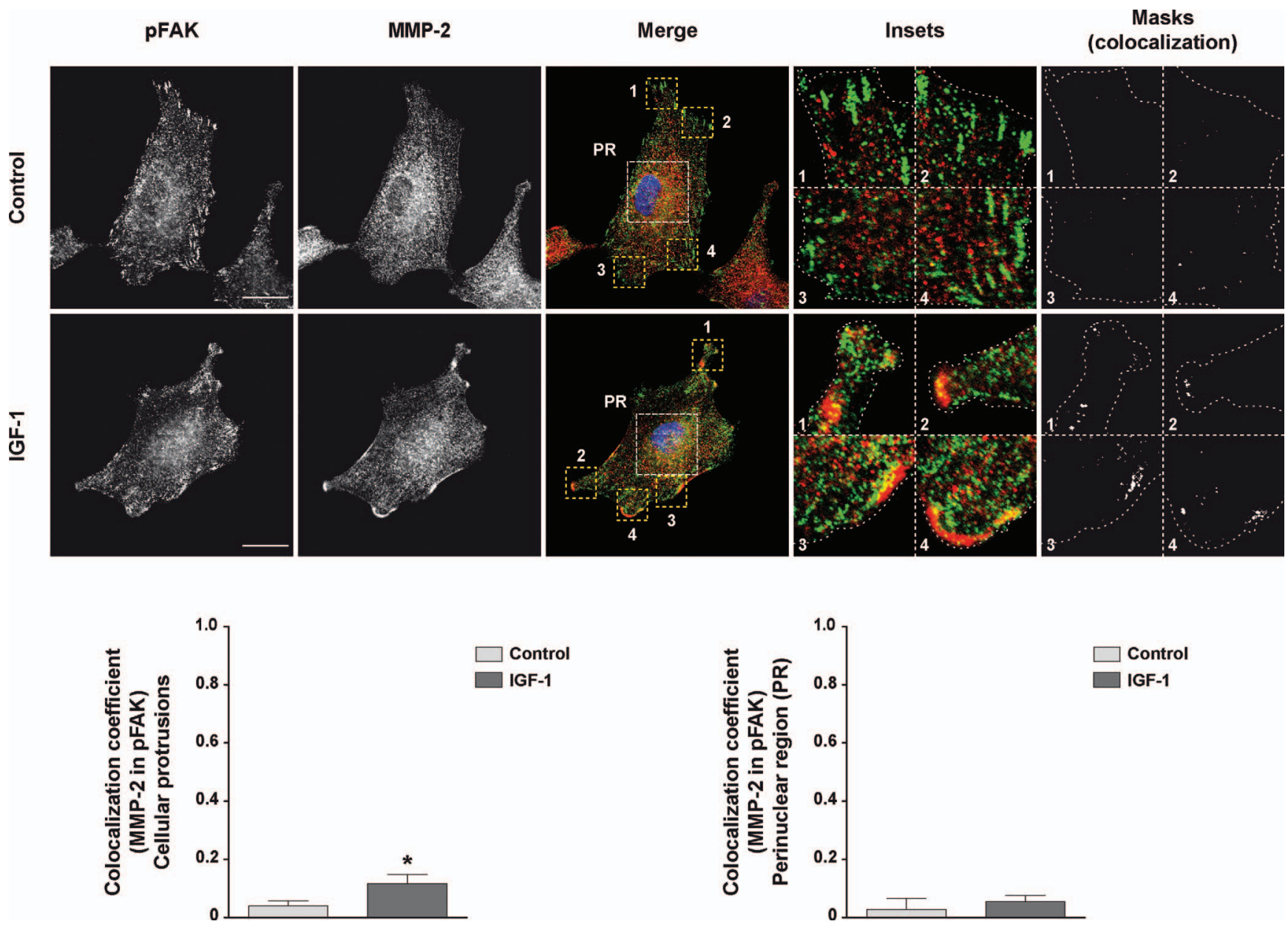

Figure 7. The p-FAK and MMP-2 colocalization is increased in MIO-M1 cells stimulated with IGF-1. The top two rows show representative images obtained by confocal microscopy. MIO-M1 cells were cultured in glass coverslips coated with Col-I in the absence (control) or presence of IGF-1 (10 nM) for 8 hours. Then, p-FAK was immunodetected using a mouse monoclonal antibody, whereas for MMP-2 a rabbit monoclonal antibody was used. The overlaid images are magnifications of the protrusions (insets 1-4) of the cells (boxes) for p-FAK and MMP-2 detection. In masks 1, 2, 3, and 4, p-FAK and MMP-2 colocalizations are observed (binary images). Quantification of colocalization levels between p-FAK and MMP-2 was performed in the peripheral and PR and is represented in the bar graph. Three independent experiments were performed in triplicate. ${ }^{*} P<0.05$ indicates statistical significance with respect to control (C). Scale bar: $20 \mu \mathrm{m}$.

migration to treat human disease. Finally, actin cytoskeleton organization and polymerization have a well-described role in cell migration. Herein, we have also shown a gelatinase/ collagenase activity coincident with F-actin filaments in IGF-1treated cells. This finding is consistent with previous studies in which the implication of MMPs in cell migration associated with the actin cytoskeleton was shown in astrocytes and olfactory ensheathing cells. ${ }^{48,69}$

Retinopathies have been classically considered to be microcirculatory diseases; however, recent evidence indicates that they are neurodegenerative retinal diseases. ${ }^{70}$ In fact, a reduction of the fiber layer and neural apoptosis prior to vascular complications has been described. ${ }^{71,72}$ At present, treatments with antiangiogenic factors, laser photocoagulation, and surgical treatments can only delay loss of vision in these patients, but in the long term, it is impossible to prevent blindness. Taking this into account, the only hope for restoration of sight is the development of stem cellbased therapies to replace the damaged neurons that could potentially integrate into the remaining neuronal network. In the retina, under certain pathologic abnormalities, MGC can undergo functional and phenotypic changes, thereby acquiring the ability to migrate toward injured sites to promote retinal remodeling and cellular repopulation..$^{73,74}$ In addition, it has been demonstrated that the humanderived MGC line, termed MIO-M1, exhibits stem cell properties and may be used for neuronal regeneration within mammalian retina. ${ }^{38,75}$ Although these transplanted cells showed an acceptable integration, survival, and neural differentiation in animal retinas with neurodegenerative damage, the success of cellular therapy was relatively poor due to the absence of migratory properties. ${ }^{74}$ Since the regulatory mechanisms that promote this MGC migration are unclear, it has been proposed that the stimulation of MIO-M1 cells with growth factors may induce the production or regulation of MMP-2 and MMP-9, facilitating the cellular migration of MGCs as well as the ECM remodeling. ${ }^{22,76}$ Interestingly, our results indicate that IGF-1, through its receptor, may be an inducing factor of MGC migration, thus facilitating cellular repopulation into the damaged host retina. More studies, however, need to be done in order to prove the migratory properties of this system in glial cells during different retinal pathologies. 


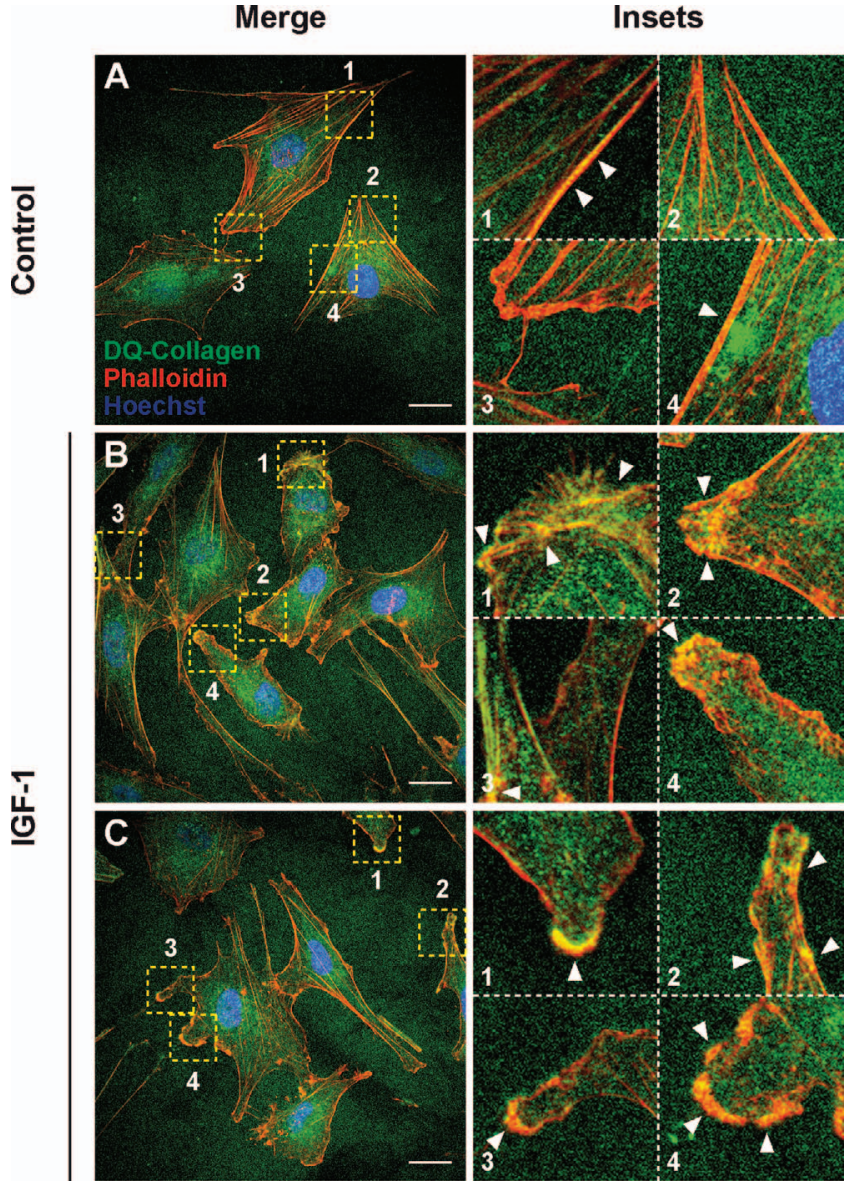

FigURE 8. IGF-1 induces increasing proteolytic activity concentrated in the MGCs migrating front. (A-C) MGCs were cultured in glass coverslips coated with Col-I in the absence (control) or presence of IGF-1 $(10 \mathrm{nM})$ and incubated for 6 hours in the presence of a collagenquenched fluorescent substrate that releases green fluorescence after enzymatic cleavage by gelatinases/collagenases. The F-actin cytoskeleton was stained with Alexa Fluor 594 phalloidin. (A-C) show representative images obtained by confocal microscopy. Insets (1-4) are the enlargement of boxed areas at peripheral regions of cells shown in (A-C). White arrowheads indicate codistribution of proteolytic activity with F-actin in the migration front (A-C) and cortical F-actin (A, B). Scale bar: $25 \mu \mathrm{m}$. Three independent experiments were performed in triplicate.

\section{Acknowledgments}

We thank Gabriela Díaz Cortez for her critical reading and language revision of the manuscript. We also thank Maria Pilar Crespo for confocal assistance and Fabricio Navarro for animal care.

Supported in part by Secretaria de Ciencia y TecnologíaUniversidad Nacional de Córdoba (SECyT-UNC) $\mathrm{N}^{\circ}$ 124/13 and 203/14; Fondo para la Investigación Científica y Tecnológica (FONCyT), Préstamo BID 2008 PICT N $^{\circ}$ 1642, PICT 2012 N $^{\circ} 2607$, and CONICET PIP 112-200801-02067.

Disclosure: V.E. Lorenc, None; J.R. Jaldín-Fincati, None; J.D. Luna, None; G.A. Chiabrando, None; M.C. Sánchez, None

\section{References}

1. Laviola L, Natalicchio A, Giorgino F. The IGF-I signaling pathway. Curr Pharm Des. 2007;13:663-669.

2. Dupont J, LeRoith D. Insulin and insulin-like growth factor I receptors: similarities and differences in signal transduction. Horm Res. 2001;55(suppl 2):22-26.
3. Bondy CA. Transient IGF-I gene expression during the maturation of functionally related central projection neurons. J Neurosci. 1991;11:3442-3455.

4. Lieskovska J, Ling Y, Badley-Clarke J, Clemmons DR. The role of Src kinase in insulin-like growth factor-dependent mitogenic signaling in vascular smooth muscle cells. J Biol Chem. 2006; 281:25041-25053.

5. Reinhardt RR, Bondy CA. Insulin-like growth factors cross the blood-brain barrier. Endocrinology. 1994;135:1753-1761.

6. Wikstrand $\mathrm{MH}$, Hård $\mathrm{AL}$, Niklasson $\mathrm{A}$, Hellström A. Birth weight deviation and early postnatal growth are related to optic nerve morphology at school age in children born preterm. Pediatr Res. 2010;6:325-329.

7. Villacampa P, Haurigot V, Bosch F. Proliferative retinopathies: animal models and therapeutic opportunities. Curr Neurovasc Res. 2015;12:189-198.

8. Meyer-Schwickerath R, Pfeiffer A, Blum WF, et al. Vitreous levels of the insulin-like growth factors I and II, and the insulinlike growth factor binding proteins 2 and 3 , increase in neovascular eye disease. Studies in nondiabetic and diabetic subjects. J Clin Invest. 1993;92:2620-2625.

9. Boulton M, Gregor Z, McLeod D, et al. Intravitreal growth factors in proliferative diabetic retinopathy: correlation with neovascular activity and glycaemic management. $\mathrm{Br} J \mathrm{Oph}$ thalmol. 1997;81:228-233.

10. Waldbillig RJ, Jones BE, Schoen TJ, et al. Vitreal insulin-like growth factor binding proteins (IGFBPs) are increased in human and animal diabetics. Curr Eye Res. 1994;13:539-546.

11. Hellstrom A, Smith LE, Dammann O. Retinopathy of prematurity. Lancet. 2013;382:1445-1457.

12. Newman E, Reichenbach A. The Müller cell: a functional element of the retina. Trends Neurosci. 1996;19:307-312.

13. Bringmann A, Pannicke T, Grosche J, et al. Müller cells in the healthy and diseased retina. Prog Retin Eye Res. 2006;25:397424 .

14. Reichenbach A, Stolzenburg JU, Eberhardt W, Chao TI, Dettmer D, Hertz L. What do retinal Müller (glial) cells do for their neuronal "small siblings"? J Chem Neuroanat. 1993; 6:201-213

15. Reichenbach A, Bringmann A. New functions of Müller cells. Glia. 2013;61:651-678.

16. Morimoto T, Miyoshi T, Matsuda S, Tano Y, Fujikado T, Fukuda Y. Transcorneal electrical stimulation rescues axotomized retinal ganglion cells by activating endogenous retinal IGF-1 system. Invest Ophthalmol Vis Sci. 2005;46:2147-2155.

17. Sato T, Fujikado T, Morimoto T, Matsushita K, Harada T, Tano Y. Effect of electrical stimulation on IGF-1 transcription by L-type calcium channels in cultured retinal Müller cells. Jpn J Ophthalmol. 2008;52:217-223.

18. Mizutani M, Gerhardinger C, Lorenzi M. Müller cell changes in human diabetic retinopathy. Diabetes. 1998;47:445-449.

19. Feist RM Jr, King JL, Morris R, Witherspoon CD, Guidry C. Myofibroblast and extracellular matrix origins in proliferative vitreoretinopathy. Graefes Arch Clin Exp Ophthalmol. 2014; 252:347-357.

20. Hiscott P, Sheridan C, Magee RM, Grierson I. Matrix and the retinal pigment epithelium in proliferative retinal disease. Prog Retin Eye Res. 1999;18:167-190.

21. Casaroli Marano RP, Preissner KT, Vilaro S. Fibronectin, laminin, vitronectin and their receptors at newly-formed capillaries in proliferative diabetic retinopathy. Exp Eye Res. 1995;60:5-17.

22. Limb GA, Daniels JT, Pleass R, Charteris DG, Luthert PJ, Khaw PT. Differential expression of matrix metalloproteinases 2 and 9 by glial Müller cells: response to soluble and extracellular matrix-bound tumor necrosis factor-alpha. Am J Pathol. 2002; 160:1847-1855. 
23. Miyata Y, Kase M, Sugita Y, et al. Protein kinase C-mediated regulation of matrix metalloproteinase and tissue inhibitor of metalloproteinase production in a human retinal Müller cells. Curr Eye Res. 2012;37;842-849.

24. Limb GA, Little BC, Meager A, et al. Cytokines in proliferative vitreoretinopathy. Eye (Lond). 1991;5(pt 6):686-693.

25. Franks WA, Limb GA, Stanford MR, et al. Cytokines in human intraocular inflammation. Curr Eye Res. 1992;11(suppl):187191.

26. Limb GA, Alam A, Earley O, Green W, Chignell AH, Dumonde DC. Distribution of cytokine proteins within epiretinal membranes in proliferative vitreoretinopathy. Curr Eye Res. 1994;13:791-798.

27. Limb GA, Chignell AH, Green W, LeRoy F, Dumonde DC. Distribution of TNF alpha and its reactive vascular adhesion molecules in fibrovascular membranes of proliferative diabetic retinopathy. Br J Ophthalmol. 1996;80:168-173.

28. Barcelona PF, Jaldín-Fincati JR, Sánchez MC, Chiabrando GA. Activated alpha2-macroglobulin induces Müller glial cell migration by regulating MT1-MMP activity through LRP1. FASEB J. 2013;27:3181-3197.

29. Chesik D, De Keyser J, Bron R, Fuhler GM. Insulin-like growth factor binding protein-1 activates integrin-mediated intracellular signaling and migration in oligodendrocytes. J Neurochem. 2010;113:1319-1330.

30. Faber-Elman A, Solomon A, Abraham JA, Marikovsky M, Schwartz M. Involvement of wound-associated factors in rat brain astrocyte migratory response to axonal injury: in vitro simulation. J Clin Invest. 1996;97:162-171.

31. Jiang J, McMurtry J, Niedzwiecki D, Goldman SA. Insulin-like growth factor- 1 is a radial cell-associated neurotrophin that promotes neuronal recruitment from the adult songbird edpendyma/subependyma. J Neurobiol. 1998;36:1-15.

32. Long L, Navab R, Brodt P. Regulation of the Mr 72,000 type IV collagenase by the type I insulin-like growth factor receptor. Cancer Res. 1998;58:3243-3247.

33. Zhang D, Bar-Eli M, Meloche S, Brodt P. Dual regulation of MMP-2 expression by the type 1 insulin-like growth factor receptor: the phosphatidylinositol 3-kinase/Akt and Raf/ERK pathways transmit opposing signals. J Biol Chem. 2004;279: 19683-19690.

34. Stetler-Stevenson WG. The role of matrix metalloproteinases in tumor invasion, metastasis, and angiogenesis. Surg Oncol Clin N Am. 2001;10:383-392, x.

35. Seiki M Yana I. Roles of pericellular proteolysis by membrane type-1 matrix metalloproteinase in cancer invasion and angiogenesis. Cancer Sci. 2003;94:569-574.

36. Sanchez MC, Luna JD, Barcelona PF, et al. Effect of retinal laser photocoagulation on the activity of metalloproteinases and the alpha(2)-macroglobulin proteolytic state in the vitreous of eyes with proliferative diabetic retinopathy. Exp Eye Res. 2007;85:644-650.

37. Grant MB, Schmetz I, Russell B, Harwood HJ Jr, Silverstein J, Merimee TJ. Changes in insulin-like growth factors I and II and their binding protein after a single intramuscular injection of growth hormone. J Clin Endocrinol Metab. 1986;63:981-984

38. Limb GA, Salt TE, Munro PM, Moss SE, Khaw PT. In vitro characterization of a spontaneously immortalized human Müller cell line (MIO-M1). Invest Ophthalmol Vis Sci. 2002; 43:864-869.

39. Kleiner DE, Stetler-Stevenson, WG. Quantitative zymography: detection of picogram quantities of gelatinases. Anal Biochem. 1994;218:325-329.

40. Rivera S, Ogier C, Jourquin J, et al. Gelatinase B and TIMP-1 are regulated in a cell- and time-dependent manner in association with neuronal death and glial reactivity after global forebrain ischemia. Eur J Neurosci. 2002;15:19-32.
41. Bolte S, Cordelieres, FP. A guided tour into subcellular colocalization analysis in light microscopy. J Microsc. 2006; 224(pt 3):213-232.

42. Li YM, Schacher DH, Liu Q, et al. Regulation of myeloid growth and differentiation by the insulin-like growth factor I receptor. Endocrinology. 1997;138:362-368.

43. Strongin AY. Proteolytic and non-proteolytic roles of membrane type-1 matrix metalloproteinase in malignancy. Biochim Biophys Acta. 2010;1803:133-141.

44. Frittoli E, Palamidessi A, Disanza A, Scita G. Secretory and endo/exocytic trafficking in invadopodia formation: the MT1MMP paradigm. Eur J Cell Biol. 2011;90:108-114.

45. Brooks PC, Strömblad S, Sanders LC, et al. Localization of matrix metalloproteinase MMP-2 to the surface of invasive cells by interaction with integrin alpha v beta 3. Cell. 1996;85: 683-693.

46. Deryugina EI, Bourdon MA, Luo GX, Reisfeld RA, Strongin A. Matrix metalloproteinase-2 activation modulates glioma cell migration. J Cell Sci. 1997;110(pt 19):2473-2482.

47. Mitra A, Chakrabarti J, Chatterjee A. Binding of alpha5 monoclonal antibody to cell surface alpha5beta1 integrin modulates MMP-2 and MMP-7 activity in B16F10 melanoma cells. J Environ Pathol Toxicol Oncol. 2003;22:167-178.

48. Ogier C, Bernard A, Chollet AM, et al. Matrix metalloproteinase-2 (MMP-2) regulates astrocyte motility in connection with the actin cytoskeleton and integrins. Glia. 2006;54:272-284.

49. Mitra SK, Hanson DA, Schlaepfer DD. Focal adhesion kinase: in command and control of cell motility. Nat Rev Mol Cell Biol. 2005;6:56-68.

50. LeRoith D, Werner H, Beitner-Johnson D, Roberts CT Jr. Molecular and cellular aspects of the insulin-like growth factor I receptor. Endocr Rev. 1995;16:143-163.

51. Lehman JA, Gomez-Cambronero J. Molecular crosstalk between p70S6k and MAPK cell signaling pathways. Biochem Biophys Res Commun. 2002;293:463-469.

52. Moelling K, Schad K, Bosse M, Zimmermann S, Schweneker M. Regulation of Raf-Akt cross-talk. J Biol Chem. 2002;277: 31099-31106.

53. Zimmermann S, Moelling K. Phosphorylation and regulation of Raf by Akt (protein kinase B). Science. 1999;286:1741-1744.

54. Risinger GM Jr, Hunt TS, Updike DL, Bullen EC, Howard EW. Matrix metalloproteinase-2 expression by vascular smooth muscle cells is mediated by both stimulatory and inhibitory signals in response to growth factors. J Biol Chem. 2006;281: 25915-25925.

55. Stawowy P, Kallisch H, Kilimnik A, et al. Proprotein convertases regulate insulin-like growth factor 1-induced membrane-type 1 matrix metalloproteinase in VSMCs via endoproteolytic activation of the insulin-like growth factor-1 receptor. Biochem Biophys Res Commun. 2004;321:31-538.

56. Artym VV, Zhang Y, Seillier-Moiseiwitsch F, Yamada KM, Mueller SC. Dynamic interactions of cortactin and membrane type 1 matrix metalloproteinase at invadopodia: defining the stages of invadopodia formation and function. Cancer Res. 2006;66:3034-3043.

57. Bravo-Cordero JJ, Marrero-Diaz R, Megías D, et al. MT1-MMP proinvasive activity is regulated by a novel Rab8-dependent exocytic pathway. EMBO J. 2007;26:1499-1510.

58. Galardy RE, Cassabonne ME, Giese C, et al. Low molecular weight inhibitors in corneal ulceration. Ann $N$ Y Acad Sci. 1994;732:315-323.

59. Sternlicht MD, Werb Z. How matrix metalloproteinases regulate cell behavior. Annu Rev Cell Dev Biol. 2001;17: 463-516.

60. Huttenlocher A, Horwitz, AR. Integrins in cell migration. Cold Spring Harb Perspect Biol. 2011;3:a005074. 
61. Wozniak MA, Modzelewska K, Kwong L, Keely PJ. Focal adhesion regulation of cell behavior. Biochim Biophys Acta. 2004;1692:103-119.

62. Gleeson LM, Chakraborty C, McKinnon T, Lala PK. Insulin-like growth factor-binding protein 1 stimulates human trophoblast migration by signaling through alpha 5 beta 1 integrin via mitogen-activated protein Kinase pathway. J Clin Endocrinol Metab. 2001;86:2484-2493.

63. Webb DJ, Parsons JT, Horwitz AF. Adhesion assembly, disassembly and turnover in migrating cells-over and over and over again. Nat Cell Biol. 2002;4:E97-E100.

64. Ridley AJ, Schwartz MA, Burridge $\mathrm{K}$, et al. Cell migration: integrating signals from front to back. Science. 2003;302: 1704-1709.

65. Friedl P, Wolf K. Plasticity of cell migration: a multiscale tuning model. J Cell Biol. 2010;188:11-19.

66. Moreno-Layseca P, Streuli CH. Signalling pathways linking integrins with cell cycle progression. Matrix Biol. 2014;34: 144-153.

67. Madamanchi A, Capozzi M, Geng L, et al. Mitigation of oxygeninduced retinopathy in alpha2beta1 integrin-deficient mice. Invest Ophthalmol Vis Sci. 2014;55:4338-4347.

68. Park SW, Yun JH, Kim JH, Kim KW, Cho $\mathrm{CH}$, Kim JH. Angiopoietin 2 induces pericyte apoptosis via alpha3beta1 integrin signaling in diabetic retinopathy. Diabetes. 2014;63: 3057-3068.
69. Gueye Y, Ferhat L, Sbai O, et al. Trafficking and secretion of matrix metalloproteinase-2 in olfactory ensheathing glial cells: A role in cell migration? Glia. 2011;59:750-770.

70. Barber AJ. A new view of diabetic retinopathy: a neurodegenerative disease of the eye. Prog Neuropsychopharmacol Biol Psychiatry. 2003;27:283-290.

71. Barber AJ, Gardner TW, Abcouwer SF. The significance of vascular and neural apoptosis to the pathology of diabetic retinopathy. Invest Ophthalmol Vis Sci. 2011;52:1156-1163.

72. Sennlaub F, Courtois Y, Goureau O. Inducible nitric oxide synthase mediates retinal apoptosis in ischemic proliferative retinopathy. J Neurosci. 2002;22:3987-3993.

73. Romo P, Madigan MC, Provis JM, Cullen KM. Differential effects of TGF-beta and FGF-2 on in vitro proliferation and migration of primate retinal endothelial and Müller cells. Acta Ophthalmol. 2011;89:e263-e268.

74. Bull ND, Limb GA, Martin KR. Human Müller stem cell (MIOM1) transplantation in a rat model of glaucoma: survival, differentiation, and integration. Invest Ophthalmol Vis Sci. 2008;49:3449-3456.

75. Lawrence JM, Singhal S, Bhatia B, et al. MIO-M1 cells and similar Müller glial cell lines derived from adult human retina exhibit neural stem cell characteristics. Stem Cells. 2007;25: 2033-2043.

76. Tackenberg MA, Tucker BA, Swift JS, et al. Müller cell activation, proliferation and migration following laser injury. Mol Vis. 2009;15:1886-1896. 